\title{
TITAN'S ORGANIC CHEMISTRY
}

\section{A PLANETARY-SCALE LABORATORY TO STUDY PRIMITIVE EARTH}

\section{ATHEna Coustenis}

Saturn's largest satellite, Titan, has been revealed by extended ground-based and space observations, and recently by the Cassini-Huygens mission. Titan's atmosphere hosts a complex organic chemistry in the solar system starting with nitrogen and methane and leading to the formation of hydrocarbons and nitriles, including prebiotic molecules. The atmosphere also contains traces of oxygen compounds. This system is subject to seasonal variations and different physical, dynamic, and photochemical processes. Interactions between the atmosphere, the surface, and the interior also play an important role in the astrobiological potential of the satellite.

Keywords: Titan, natural satellites, atmosphere, organic chemistry.

\section{TITAN'S ATMOSPHERE: AN EXCEPTIONAL AND} ENIGMATIC COMPONENT

It has been known for more than a century now that Titan, Saturn's largest satellite, possesses a substantial atmosphere, the one most similar to our own planet's among the other objects of our solar system, because it is essentially composed of molecular nitrogen $\left(\mathrm{N}_{2}\right)$, with traces of methane and hydrogen, leading to one of the most complex organic chemistries from among all the objects in our solar system. Indeed, as early as 1944, Gerard Kuiper and some other scientists discovered methane and several other hydrocarbons in Titan's atmosphere: ethane $\left(\mathrm{C}_{2} \mathrm{H}_{6}\right)$, mono-deuterated methane $\left(\mathrm{CH}_{3} \mathrm{D}\right)$, ethylene $\left(\mathrm{C}_{2} \mathrm{H}_{4}\right)$ and acetylene $\left(\mathrm{C}_{2} \mathrm{H}_{2}\right)$.

The Voyager missions in the 1980s brought in a lot of information on Titan's characteristics and its atmosphere in terms of temperature and structure, but also uncovered the thick layer of cloud underneath which the optical range of the satellite's surface was hidden.

The advent of the Cassini-Huygens mission in 2004 and its extensive exploration of the Saturnian system, and Titan in particular, provided the scientific community with a new and more detailed picture of Titan's atmospheric chemistry, which is closely related to the satellite's complex seasonal variations, as well as its dynamic effects and climate for the past 10 years.

\section{TITAN'S THERMAL STRUCTURE}

Adding to the Voyager 1 radio occultation data, measurements by the Composite Infrared Radiometer

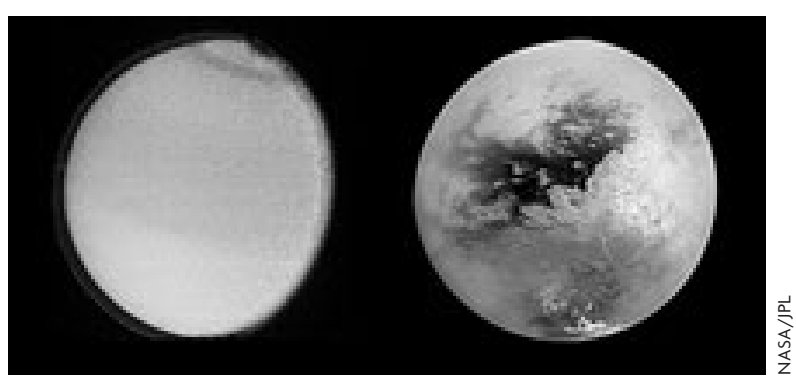

Figure 1. Titan, observed in 1980 with the Voyager 1 cameras in the visible range and in 2004 with the Cassini ISS camera at $0.94 \mu \mathrm{m}$.

Titan's orbital and body parameters, and atmospheric properties
\begin{tabular}{ll} 
Surface radius & $2,575 \mathrm{~km}$ \\
\hline Mass & $1.35 \times 10^{23} \mathrm{~kg}(=0,022 \times$ Earth $)$ \\
\hline Mean density & $1880 \mathrm{~kg} \mathrm{~m}^{-3}$ \\
\hline Distance from Saturn & $1.23 \times 10^{9} \mathrm{~m}(=20$ Saturn radii) \\
\hline Distance from Sun & $9.546 \mathrm{AU}$ \\
\hline Orbital period & 15.95 days \\
\hline Revolution around Sun & 29.5 years \\
\hline Obliquity & $26.7^{\circ}$ \\
\hline Surface temperature & $93.6 \mathrm{~K}$ \\
\hline Surface pressure & $1.467 \mathrm{bar}$ \\
\hline
\end{tabular}

Table 1. Titan's characteristics. Titan is the largest Saturnian satellite. SOuRCE: Coustenis, A. (2014). Titan. In T. Spohn, D. Breuer, \& T. V. Johnson (Eds.), Encyclopedia of the Solar System (pp. 831-850). 3rd edition. Amsterdam: Elsevier.

"THE VOYAGER MISSIONS IN THE 1980s

BROUGHT IN A LOT OF INFORMATION ON TITAN'S CHARACTERISTICS" 
Spectrometer (CIRS) on the orbiter and from the Huygens Atmospheric Structure Instrument (HASI) taken at the probe's landing site $\left(10^{\circ} \mathrm{S}, 192^{\circ} \mathrm{W}\right)$, and from an altitude of $1400 \mathrm{~km}$ down to the surface, allowed us to reconstruct the temperature structure of Titan. A surface temperature of $93.65 \pm 0.25$ $\mathrm{K}$ was measured for a pressure of $1467 \pm 1 \mathrm{mbar}$ (Fulchignoni et al., 2005). As Voyager had shown before, the data indicated that Titan's atmosphere was composed (from its upper altitudes to the lower ones) of a thermosphere, mesosphere, stratosphere, and troposphere, with two major temperature inversions at 40 and $250 \mathrm{~km}$, corresponding to the tropopause and stratopause, associated with temperatures of 70.43 $\mathrm{K}(\mathrm{min})$ and $186 \mathrm{~K}$ (max). A mesopause was also found at $490 \mathrm{~km}$ (with $152 \mathrm{~K}$ ) in the early years of the Cassini mission, but has gradually disappeared in the recent years, leading to a more homogeneous profile.

No significant changes in temperature were reported for the inter-annual time lapse, but extreme changes between seasons, essentially at the poles, were found, with the southern pole being currently extremely cold and having reached that state in a short period of time (within a couple of years, Coustenis et al., 2013; 2015).

Ninety percent of the energy at the surface of Titan is held in by a greenhouse effect due to nitrogen, methane, and hydrogen; these symmetrical molecules do not normally have a greenhouse effect on Earth but they do on Titan due to the dense atmosphere. This opacity blocks the thermal emission reflected by the surface, thus causing the lower part of the atmosphere to heat up, as on Earth, where water is the major player. Even more interestingly, Titan is the only world in the solar system that has an antigreenhouse effect that lets light in and stops infrared, caused by the haze layers in the atmosphere. The anti-greenhouse effect on Titan is half as strong as the greenhouse effect. The tropospheric emission temperature (near the tropopause) is determined by the anti-greenhouse effect and is $9 \mathrm{~K}$ cooler than the effective temperature (McKay, 2005). The increase in temperature from the tropopause to the surface is due to a $21 \mathrm{~K}$ greenhouse effect resulting from thermal IR radiation $(113 \%)$ emitted from the lower atmosphere and warming the surface.

\section{TITAN'S CHEMICAL COMPOSITION}

Titan's atmosphere is a chemical factory in which the formation of complex positive and negative ions is initiated in the high thermosphere as a consequence of magnetospheric-ionospheric-atmospheric

\begin{tabular}{|c|c|}
\hline Constituent & Mole fraction (atmospheric altitude level) \\
\hline \multicolumn{2}{|l|}{ MAJOR } \\
\hline Molecular nitrogen, $\mathrm{N}_{2}$ & 0.98 \\
\hline \multirow{2}{*}{ Methane, $\mathrm{CH}_{4}$} & $4.9 \times 10^{-2}$ (surface) \\
\hline & $1.4-1.6 \times 10^{-2}$ (stratosphere) \\
\hline Mono-deuterated methane, $\mathrm{CH}_{3} \mathrm{D}$ & $6 \times 10^{-6}$ (stratosphere) \\
\hline Argon, ${ }^{36} \mathrm{Ar}$ & $2.8 \times 10^{-7}$ \\
\hline${ }^{40} \mathrm{Ar}$ & $4.3 \times 10^{-5}$ \\
\hline \multicolumn{2}{|l|}{ MINOR } \\
\hline Hydrogen, $\mathrm{H}_{2}$ & $\sim 0,0011$ \\
\hline Ethane, $\mathrm{C}_{2} \mathrm{H}_{6}$ & $1.5 \times 10^{-5}$ (around $\left.130 \mathrm{~km}\right)$ \\
\hline Propane, $\mathrm{C}_{3} \mathrm{H}_{8}$ & $5 \times 10^{-7}$ (around $125 \mathrm{~km}$ ) \\
\hline Acetylene, $\mathrm{C}_{2} \mathrm{H}_{2}$ & $4 \times 10^{-6}$ (around $\left.140 \mathrm{~km}\right)$ \\
\hline Ethylene, $\mathrm{C}_{2} \mathrm{H}_{4}$ & $1.5 \times 10^{-7}$ (around $\left.130 \mathrm{~km}\right)$ \\
\hline Methylacetylene, $\mathrm{CH}_{3} \mathrm{C}_{2} \mathrm{H}$ & $6.5 \times 10^{-9}(\text { around } 110 \mathrm{~km})^{a}$ \\
\hline Diacetylene, $\mathrm{C}_{4} \mathrm{H}_{2}$ & $1.3 \times 10^{-9}(\text { around } 110 \mathrm{~km})^{a}$ \\
\hline Cyanogen, $\mathrm{C}_{2} \mathrm{~N}_{2}$ & $5.5 \times 10^{-9}(\text { around } 120 \mathrm{~km})^{a}$ \\
\hline \multirow[t]{3}{*}{ Hydrogen cyanide, $\mathrm{HCN}$} & $1.0 \times 10^{-7}(\text { around } 120 \mathrm{~km})^{a}$ \\
\hline & $5 \times 10^{-7}(\text { around } 200 \mathrm{~km})^{b}$ \\
\hline & $5 \times 10^{-6}(\text { around } 500 \mathrm{~km})^{b}$ \\
\hline \multirow[t]{2}{*}{ Cyanoacetylene, $\mathrm{HC}_{3} \mathrm{~N}$} & $1 \times 10^{-9}(\text { around } 120 \mathrm{~km})^{a}$ \\
\hline & 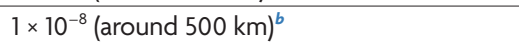 \\
\hline \multirow[t]{2}{*}{ Acetonitrile, $\mathrm{CH}_{3} \mathrm{CN}$} & $1 \times 10^{-8}(\text { around } 200 \mathrm{~km})^{c}$ \\
\hline & $1 \times 10^{-7}$ (around $\left.500 \mathrm{~km}\right)$ \\
\hline Water, $\mathrm{H}_{2} \mathrm{O}$ & $8 \times 10^{-9}(\mathrm{a} 400 \mathrm{~km})^{d}$ and $10^{-10}(\mathrm{a} 200 \mathrm{~km})^{e}$ \\
\hline Carbon monoxide, $\mathrm{CO}$ & $4 \times 10^{-5}$ (uniform profile) $^{f}$ \\
\hline Carbon dioxide, $\mathrm{CO}_{2}$ & $1.5 \times 10^{-8}$ (around $\left.120 \mathrm{~km}\right)$ \\
\hline $\begin{array}{l}{ }^{a} \text { Increasing in the north. } \\
{ }^{b} \text { From ground-based heter } \\
{ }^{c} \text { Only observed from the } g \\
{ }^{d} \text { From ISO observations. } \\
{ }^{e} \text { From Cassini/CIRS. } \\
{ }^{f} \text { From Cassini and ground- }\end{array}$ & $\begin{array}{l}\text { odyne microwave observations. } \\
\text { round. }\end{array}$ \\
\hline
\end{tabular}

Table 2. Chemical composition of Titan's atmosphere from CassiniHuygens.

SOURCE: Coustenis, A. (2014). Titan. In T. Spohn, D. Breuer, \& T. V. Johnson (Eds.), Encyclopedia of the Solar System (pp. 831-850). 3rd edition. Amsterdam: Elsevier, and references therein. The numbers are from results by Cassini-Huygens unless otherwise indicated.

\footnotetext{
"DIRECT ANALYSIS OF THE IONOSPHERE BY THE INMS INSTRUMENT DURING THE LOW ALTITUDE CASSINI FLYBYS OF TITAN SHOWED THE PRESENCE OF MANY ORGANIC SPECIES"
} 
interactions involving solar extreme ultraviolet (EUV) and UV radiation, energetic ions, and electrons (Waite et al., 2007).

In the neutral atmosphere, methane $\left(\mathrm{CH}_{4}\right)$ chemistry is coupled with molecular nitrogen $\left(\mathrm{N}_{2}\right)$ producing many organic molecules in the gas and condensate phase: hydrocarbons, nitriles, and complex refractory organics that produce tholins, which have been hypothesized and simulated in the laboratory (Waite et al., 2007; Coll, Guillemin, Gazeau, \& Raulin, 1999). Molecular nitrogen (detected in the UV range) is by far the biggest component of the atmosphere (averaging more than $95 \%$ ). The presence of methane (the next most abundant molecule with a mixing ratio of about $1.5 \%$ in the stratosphere and $5 \%$ at the surface) and of traces of hydrogen give rise to a host of organic gases and haze whose presence in the stratosphere had been established since the twentieth century.

\section{THE IONOSPHERIC CHEMISTRY}

Titan was found to have quite an extended ionosphere, essentially due to the lack of a strong intrinsic global magnetic field. High-energy photons (EUV and X-rays) and energetic particles from Saturn's magnetosphere are the main energy sources in Titan's upper atmosphere and create an extended ionosphere between 700 and $2700 \mathrm{~km}$. At lower altitudes, galactic cosmic rays (GCR) are responsible for the production of another ion-layer in the atmosphere (between 40 and 140 $\mathrm{km}$ ), while the neutral atmospheric photochemistry is mainly driven by FUV solar photons.

Direct analysis of the ionosphere by the INMS instrument during the low altitude Cassini flybys of Titan showed the presence of many organic species at detectable levels, in spite of the very high altitude (Waite et al., 2007, Figure 2).

These observations open new avenues in our perception of the organic processes occurring in Titan's atmosphere, with a strong implication of the ionospheric chemistry in the formation of high-level organic compounds in Titan's environment, which was not envisaged before. As the haze particles fall through the atmosphere and grow, they become detectable with imaging systems such as the Cassini/ Imaging SubSystem (ISS) at the $\sim 500 \mathrm{~km}$ altitude and are ubiquitous throughout the stratosphere (Porco et al., 2005). They are strong absorbers of solar UV

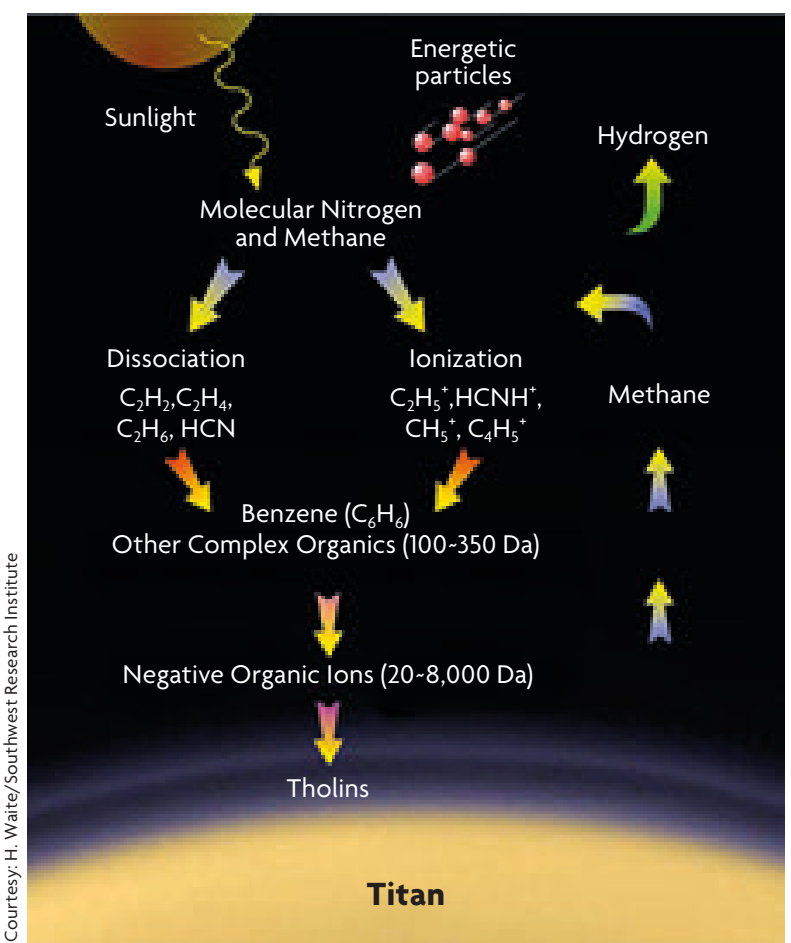

Figure 2. Schematic of Titan's complex organic chemistry

and visible radiation and play a fundamental role in heating Titan's stratosphere and driving wind systems in the middle atmosphere, much as ozone does in the Earth's middle atmosphere.

\section{THE NEUTRAL CHEMISTRY}

Cassini has recently provided accurate spatial (latitudinal and vertical) distributions of the trace gases (Figure 3). The vertical distributions generally increase with altitude, confirming the prediction of photochemical models that these species form in the upper atmosphere and then diffuse downward in the stratosphere. Below the condensation level of each gas, the distributions are assumed to decrease following the respective vapor saturation law. Among the gaseous species detected to date we find hydrocarbons and nitriles but traces of water vapor were also detected in Titan's atmosphere (Coustenis et al., 1998), as well as benzene by Cassini/ CIRS and INMS (Flasar, 2005).

Ground-based high-resolution heterodyne millimeter observations of Titan offered the opportunity to determine vertical profiles and in some cases, partial mapping, of $\mathrm{HCN}, \mathrm{CO}, \mathrm{HC}_{3} \mathrm{~N}$, and $\mathrm{CH}_{3} \mathrm{CN}$, which showed that the nitrile abundances 

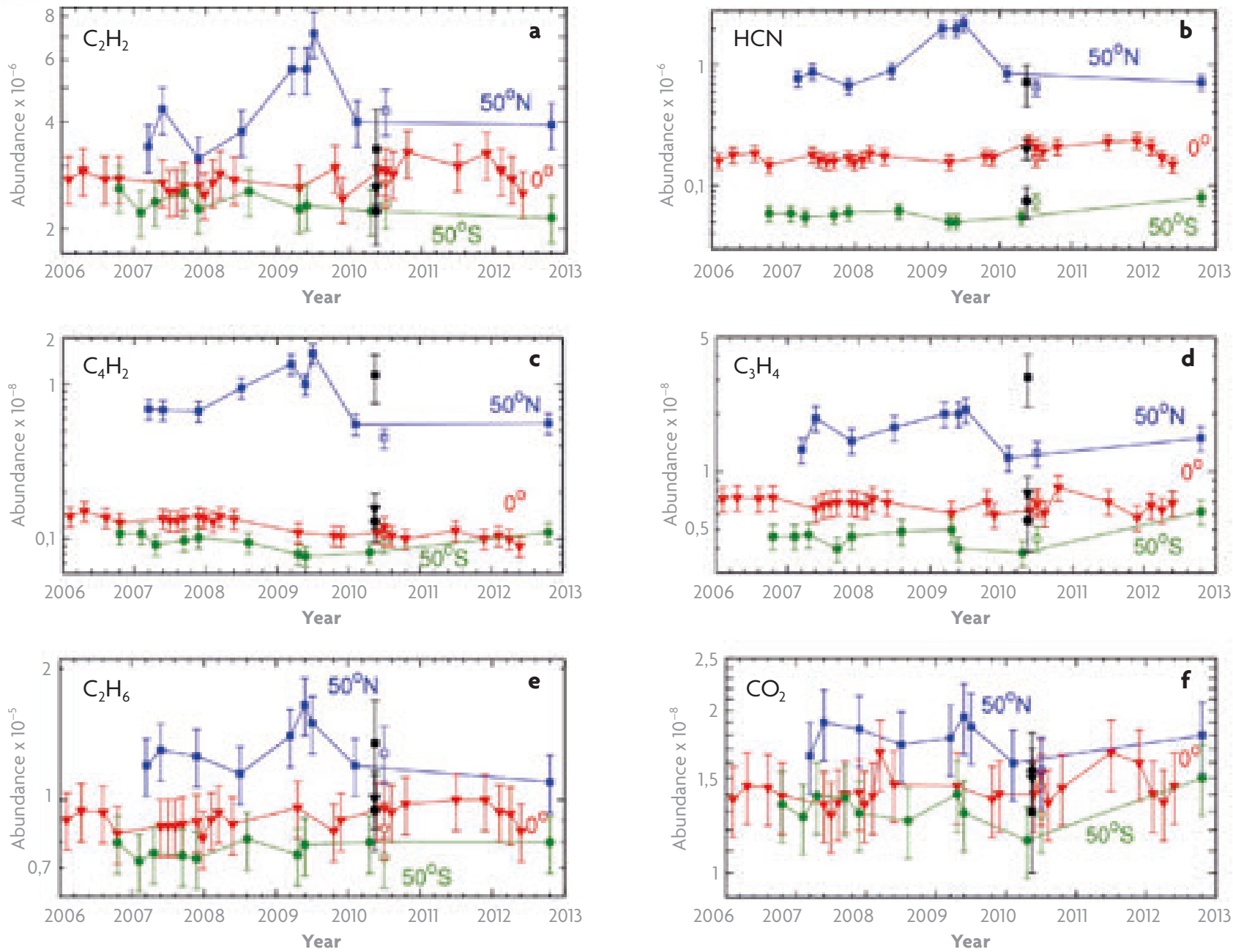

Figure 3. Variations of the abundances of gases in Titan's stratosphere during the Cassini mission at $50^{\circ} \mathrm{S}$ (green full circles and lines), the equator (red full triangles and lines), and $50^{\circ} \mathrm{N}$ (blue full squares and lines) inferred from high-resolution nadir data for: $\boldsymbol{a}$ ) $\left.\mathrm{C}_{2} \mathrm{H}_{2}, \boldsymbol{b}\right) \mathrm{HCN}$, c) $\mathrm{C}_{4} \mathrm{H}_{2}$, d) $\mathrm{C}_{3} \mathrm{H}_{4}$, e) $\mathrm{C}_{2} \mathrm{H}_{6}$ and $\boldsymbol{f}$ ) $\mathrm{CO}_{2}$. The open symbols correspond to mixing ratio inferences from medium-resolution $\left(2.5 \mathrm{~cm}^{-1}\right)$ data that we had in 2010. The black symbols and vertical lines correspond to the recalculated Voyager 1/IRIS abundances and error bars.

SOURCE: Coustenis et al., 2013.

increase with altitude. Subsidence causes the abundance of these species to decrease in the lower atmosphere.

Closer to the ground, Cassini-Huygens finally allowed the major components to be confidently determined: consistently with CIRS measurements in the stratosphere, the Huygens Gas Chromatograph Mass Spectrometer (GCMS) found a methane mole fraction of $(1.48 \pm 0.1) \times 10^{-2}$ in the stratosphere, increasing below the tropopause, and reaching $5.65 \times 10^{-2}$ near the surface, in agreement with the CIRS stratospheric values and the surface estimate given by the Huygens Descent Imager Spectral Radiometer (DISR) spectra (also roughly $5 \%$, Tomasko et al., 2005). The GCMS also saw a rapid increase in the methane signal after the landing, which suggests that liquid methane exists on the surface, together with other trace organic species, including cyanogen, benzene, ethane, and carbon dioxide (Niemann et al., 2010).

\section{SPATIAL AND TEMPORAL VARIATIONS OF THE CHEMISTRY AND THE CIRCULATION}

Meridional variations were established for the gases in Titan's stratosphere, and these are tightly coupled with their circulation. The molecular abundances found by Cassini at that time (one Titan year after the V1 encounter) indicate an enhancement for most species in the stratosphere at high latitudes, with values similar to those observed 30 years ago, with a few exceptions (Figure 4). 
Such latitudinal contrasts observed in the chemical trace species may be explained by photochemical and dynamic causes. The UV radiation from the Sun acts on methane and nitrogen to form radicals that combine into nitriles and the higher hydrocarbons.

This production occurs in the mesosphere at high altitudes (above $300 \mathrm{~km}$ or $0.1 \mathrm{mbar}$ ). Mixing by eddies transports these molecules into the lower stratosphere and troposphere where most of them condense. Photodissociation by UV radiation occurs on timescales ranging from days to thousands of years.

A strong seasonal cycle due to Titan's obliquity of $26.7^{\circ}$ was established: during most of the Titan year, the meridional motion is dominated by a large Hadley cell extending from the winter to the summer pole, with the symmetric two-cell configuration typical of equinoxes occurring only in a limited transition period. In models, the jet is located close to $60^{\circ}$ in the winter hemisphere, while the summer zonal circulation is close to solid body rotation.

\section{HAZE AND CLOUDS ON TITAN}

It was recognized quite early on that another important aspect of Titan's atmosphere was the presence therein of aerosols. Starting from the upper atmosphere, the rich chemical composition observed in the thermosphere, along with the detection of large mass ions, hinted at the formation of aerosols in the ionosphere; this was supported by observations from the Ultra Violet Imaging Spectrometer (UVIS) that detected aerosols up to $\sim 900 \mathrm{~km}$ of altitude, as well as by the detection of large-mass negative ions in the ionosphere by the Cassini Plasma spectrometer (CAPS).

In the mesosphere the Cassini ISS camera showed a faint thin haze layer that encircles the denser stratospheric haze. Cassini images also show a multilayer structure in the north polar hood region and, in some cases, at lower latitudes. These features could be due to gravity waves that have been detected on Titan at lower latitudes.

The nature of the haze aerosols measured by Huygens/DISR during the descent through Titan's lower atmosphere indicate that the size of the aggregate particles is several times larger than previously supposed (Tomasko et al., 2005). DISR data are compatible with a thin haze layer at an altitude of 21 $\mathrm{km}$, which could be due to methane condensation.

Cassini-Huygens has provided new information on the role of methane and the methane cycle in Titan's

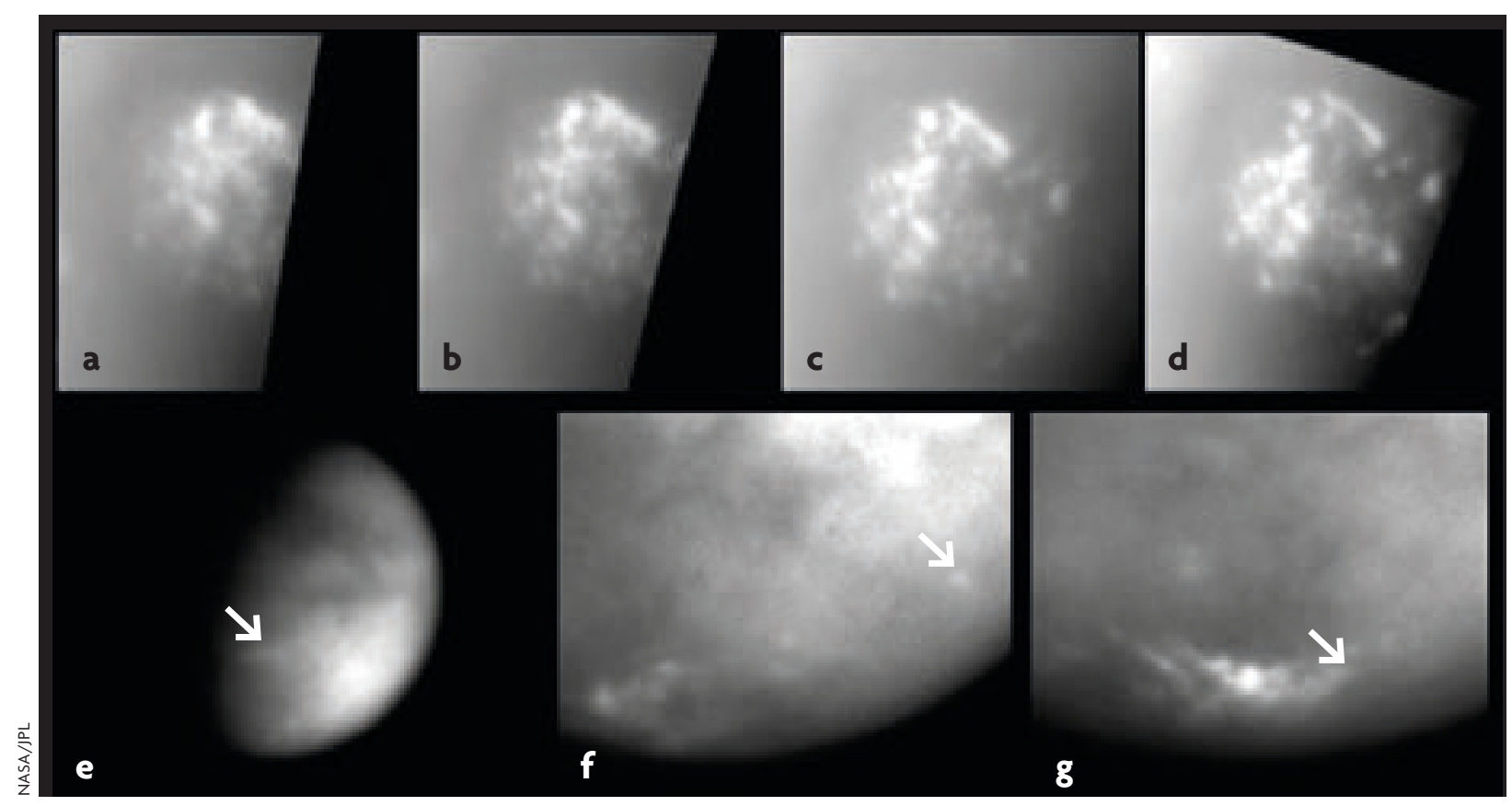

Figure 4. Titan's meteorology observed with Cassini/ISS. From $\boldsymbol{a}$ ) to $\boldsymbol{d}$ ), sequence of four methane continuum images showing the temporal evolution of the south polar cloud field on 2 July 2004. From $\boldsymbol{e}$ ) to $\boldsymbol{g}$ ), three examples of discrete mid-latitude clouds (arrows). SOURCE: Porco et al., 2005 
a

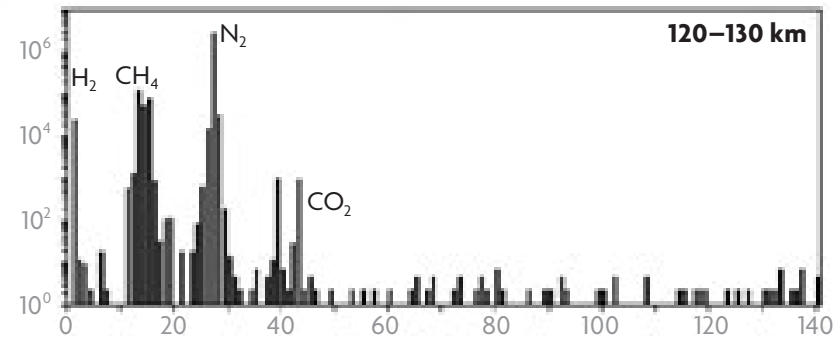

b

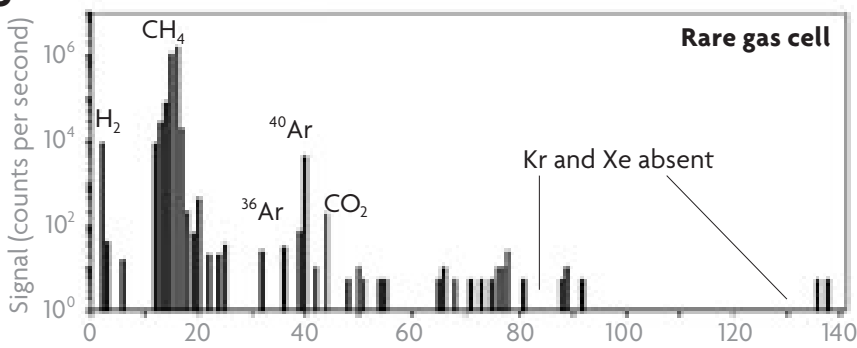

C

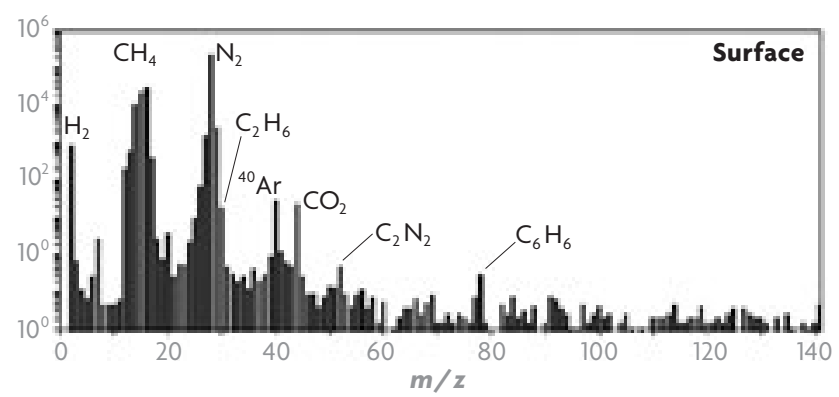

Figure 5. Titan's atmosphere and surface composition from mass spectra from the GCMS instrument on the Huygens probe at various altitudes. These sample-averaged spectra show the ion count rates per second as a function of unit charge $(\mathrm{m} / \mathrm{z})$, either at 120-130 km (a), or at 75-77 in the rare gas cell $(\boldsymbol{b})$, or at the surface (c).

SOURCE: Niemann et al., 2005.

atmosphere. The relative humidity of methane at the surface (about $50 \%$ ) found by DISR and the evaporation observed by the GCMS show that fluid flows have existed and will probably exist again on the surface, implying precipitation of methane through the atmosphere.

The methane mole fraction of 1.4-1.6\% measured in the stratosphere by the CIRS and the GCMS is consistent with the DISR spectral measurements. At very low altitudes $(20 \mathrm{~m})$, DISR and the GCMS measured $5 \pm 1 \%$ for the methane mole fraction.

Surprisingly, the Huygens GCMS has not detected a large variety of organic compounds in the lower atmosphere. The mass spectra collected during the descent show that the medium and low stratosphere and the troposphere are poor in volatile organic species, with the exception of methane (Niemann et al., 2005). GCMS detected on the surface not only methane, but also a host of other condensed material among which were $\mathrm{C}_{2} \mathrm{H}_{6}, \mathrm{CO}_{2}, \mathrm{C}_{2} \mathrm{~N}_{2}$, and $\mathrm{C}_{6} \mathrm{H}_{6}$ (Figure 5).

The aerosols, for which no direct data on the chemical composition were previously available, were analyzed by the Aerosol Collector Pyrolyzer (ACP) instrument. ACP results show that the aerosol particles are made of refractory organics which release $\mathrm{HCN}$ and $\mathrm{NH}_{3}$ during pyrolysis (Israël et al., 2005 , supporting the tholin hypothesis).

\section{ASTROBIOLOGICAL IMPLICATIONS}

All the ingredients which are supposed to be necessary for life to appear and be supported - liquid water, organic matter and energy - seem present on Titan (Coustenis \& Encrenaz, 2013).

With the current picture of Titan's organic chemistry, the chemical evolution of the main atmospheric constituents - dinitrogen and methaneproduces mainly ethane which accumulates on the surface or the near sub-surface and which eventually dissolves in the methane-ethane lakes and seas (Raulin, 2008; Figure 6), and refractory organics which accumulate on the surface, together with condensed volatile organic compounds such as $\mathrm{HCN}$ and benzene. In spite of the low temperature, contrary to what was often said, Titan is not a solidified Earth: the chemical system is not frozen. Titan is an evolving planetary body and so is its chemistry. Once sedimented on Titan's surface, the aerosols and their complex organic content may chemically evolve in ways that are of astrobiological interest.

Gravitation and spin measurements by Cassini indicate the presence of a liquid water undersurface ocean on Titan. Thermal evolution models suggest that Titan may have an ice crust between 50 and 150 $\mathrm{km}$ thick lying on top of a liquid water ocean a couple of hundred kilometers deep, with some amount (a few to $30 \%$, most likely $\sim 10 \%$ ) of ammonia dissolved in it, acting as an antifreeze (Iess et al., 2012). Beneath lies a layer of high-pressure ice.

Titan is the only body other than the Earth in our solar system to present such a complex organic chemistry and exposed liquid bodies on the surface. With the additional possibility for an under-surface liquid water ocean, Titan appears to be an ideal candidate for a habitable world in the solar system.

\section{REFERENCES}

Coll, P., Guillemin, J. C., Gazeau, M. C., \& Raulin, F. (1999). Report and implications of the first observation of $\mathrm{C}_{4} \mathrm{~N}_{2}$ in laboratory simulations of Titan's atmosphere. Planetary and Space Science, 47, 1433-1440. doi: 10.1016/S0032-0633(99)00069-0 


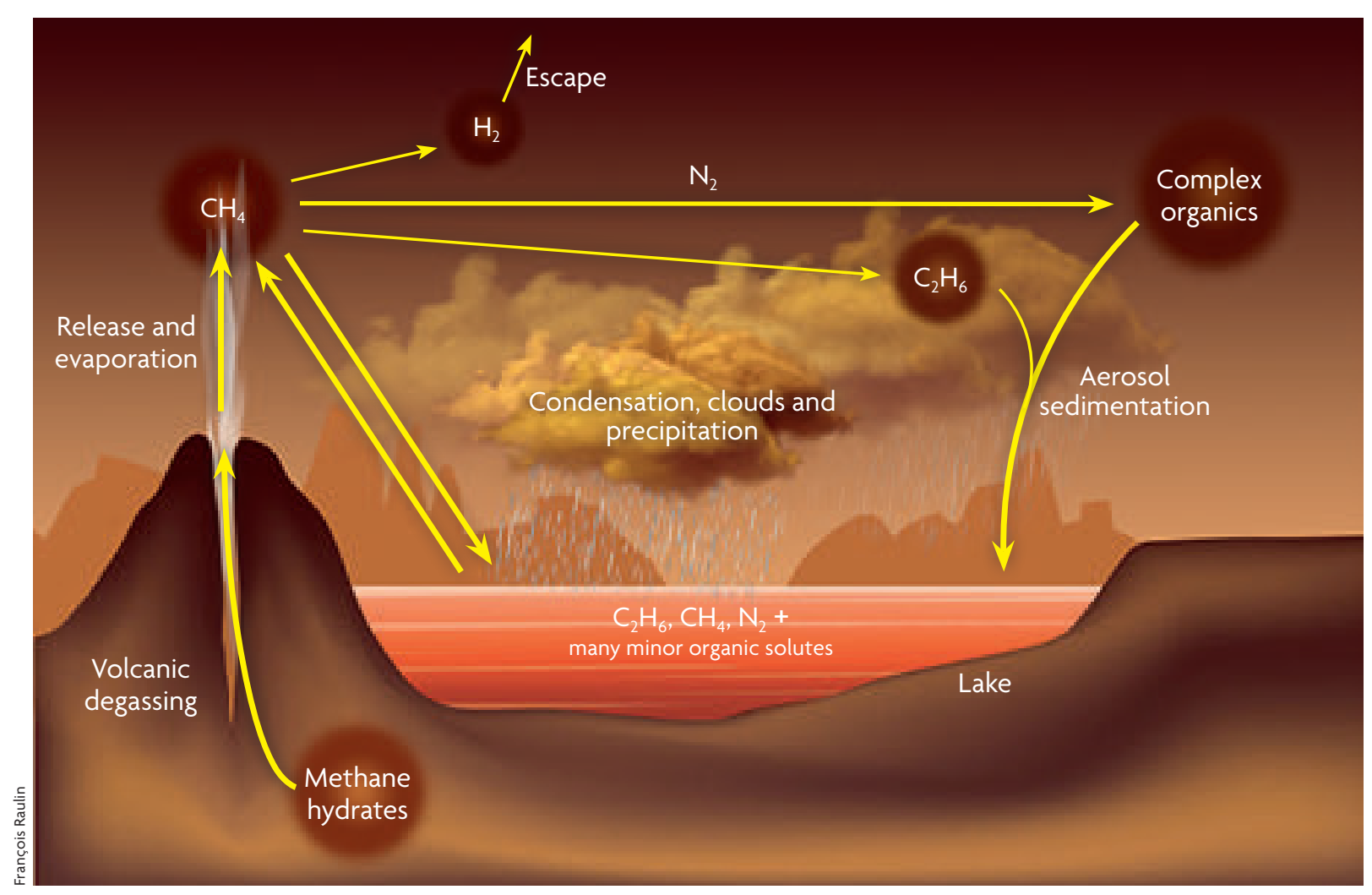

Figure 6. Titan's organic lakes and their interaction with the interior and the atmosphere. The methane cycle on Titan and the resulting processes are depicted here.

Coustenis, A., \& Encrenaz, Th. (2013). Life beyond Earth: The search for habitable worlds in the universe. Cambridge: Cambridge University Press. Coustenis, A., Salama, A., Lellouch, E., Encrenaz, Th., Bjoraker, G. L., Samuelson, R. E., ... Kessler, M. F. (1998). Evidence for water vapor in Titan's atmosphere from ISO/SWS data. Astronomy and Astrophysics, 336(3), L85-L89.

Coustenis, A., Bampasidis, G., Achterberg, R. K., Lavvas, P., Jennings, D. E., Nixon, C. A., ... Stamogiorgos, S. (2013). Evolution of the stratospheric temperature and chemical composition over one Titanian year. The Astrophysical Journal, 779, 177-185. doi: 10.1088/0004$637 \mathrm{X} / 779 / 2 / 177$

Coustenis, A., Jennings, D. E., Achterberg, R. K., Bampasidis, G., Lavvas, P., Nixon, C. A., ... Flasar, F. M. (2015). Titan's temporal evolution in stratospheric trace gases near the poles. Icarus. doi: 10.1016/ j.icarus.2015.08.027

Flasar, F. M., Achterberg, R. K., Conrath, B. J., Gierasch, P. J., Kunde, V. G., Nixon, C. A., ... Wishnow, E. H. (2005). Titan's atmospheric temperatures, winds, and composition. Science, 308(5724), 975-978. doi: $10.1126 /$ science. 1111150

Fulchignoni, M., Ferri, F., Angrilli, F., Ball, A. J., Bar-Nun, A., Barucci, M. A., ... ZRNAecki, J. C. (2005). In situ measurements of the physical characteristics of Titan's environment. Nature, 438, 785-791. doi: 10.1038/ nature 04314

Iess, L., Jacobson, R. A., Ducci, M., Stevenson, D. J., Lunine, J. I., Armstrong, J. W., ... Tortora, P. (2012). The tides of Titan. Science, 337(6093), 457-459. doi: 10.1126/science.1219631

Israël, G., Szopa, C., Raulin, F., Cabane, M., Niemann, H. B., Atreya, S. K., ... Vidal-Madjar, C. (2005). Complex organic matter in Titan's atmospheric aerosols from in situ pyrolysis and analysis. Nature, 438 , 796-799. doi: 10.1038/nature04349

McKay, C. (2005, November 3). Titan: Greenhouse and anti-greenhouse. Astrobiology Magazine. Retrieved from http://www.astrobio.net/topic/ solar-system/saturn/titan/titan-greenhouse-and-anti-greenhouse/
Niemann, H. B., Atreya, S. K., Bauer, S. J., Carignan, G. R., Demick, J. E., Frost, R. L., ... Way, S. H. (2005). The abundances of constituents of Titan's atmosphere from the GCMS instrument on the Huygens probe. Nature, 438, 779-784. doi: 10.1038/nature04122

Niemann, H. B., Atreya, S. K., Demick, J. E., Gautier, D., Haberman, J. A., Harpold, D. N., ... Raulin, F. (2010). Composition of Titan's lower atmosphere and simple surface volatiles as measured by the CassiniHuygens probe gas chromatograph mass spectrometer experiment. Journal of Geophysical Research, 115(12), 2156-2202. doi: 10.1029/2010JE003659

Porco, C. C., Baker, E., Barbara, J., Beurle, K., Brahic, A., Burns, J. A., ... West, R. (2005). Imaging of Titan from the Cassini spacecraft. Nature, 434, 159-168. doi: 10.1038/nature03436

Raulin, F. (2008). Planetary science: Organic lakes on Titan. Nature, 454, 587-589. doi: 10.1038/454587a

Tomasko, M. G., Archinal, B., Becker, T., Bézard, B., Bushroe, M., Combes, M., ... West, R. (2005). Rain, winds and haze during the Huygens probe's descent to Titan's surface. Nature, 438, 765-778. doi: 10.1038/ nature 04126

Waite, J. H., Young, D. T., Cravens, T. E., Croates, A. J., Crary, F. J., Magee, B., \& Westlake, J. (2007). The process of tholin formation in Titan's upper atmosphere. Science, 316(5826), 870-875. doi: 10.1126/ science. 1139727

Athena Coustenis. Director of Research with the CNRS at the Paris Observatory, specializing in planetology and space missions to the outer solar system. She is the President of the Space Sciences Committee of the European Science Foundation and a member of the International Space Science Institute Executive Committee. She is on the Editorial Boards of Astronomy \& Astrophysics Review, Astronomy and Astrophysics Library, and Philosophical Transactions A. 